\title{
Dr. Tatsuhiko Sato: a new model for estimating therapeutic effect of BNCT using the PHITS code
}

Received: 01 November 2018; Accepted: 25 November 2018; Published: 28 November 2018.

doi: $10.21037 /$ tro.2018.11.02

View this article at: http://dx.doi.org/10.21037/tro.2018.11.02

\section{Editor's note}

The 18th International Congress on Neutron Capture Therapy was held successfully for the first time in Taipei, Taiwan from October 28 through November 2, 2018. The congress was spread over six days and featured training courses, parallel sessions, plenary talks, invited lectures, and poster viewing and presentations.

This conference was composed of world-renowned multidisciplinary experts from industry and academia, working together on the goals of cancer treatment. Just like the theme "Precision Therapy, Beautiful Tomorrow-We Here, We Care", there are a number of encouraging findings were presented and constructive discussions were held during the congress. With these ongoing developments, the promise of boron neutron capture therapy as a standard radiation therapy for cancer is becoming a reality.

At the congress, Dr. Tatsuhiko Sato gave an impressive speech on "Macro- and microdosimetry for BNCT based on PHITS." We had the great honor to interview Dr. Sato to have an exclusive interview and talk about the model he recently developed using the PHITS code. Dr. Sato also shared with us the reasons behind his choice to start the BNCT research (Figure 1).

\section{Expert introduction}

Tatsuhiko Sato (Figure 2) is a researcher in Nuclear Science and Engineering Cancer at Japan Atomic Energy Agency (JAEA), Japan. He is also a member of International Commission on Radiological Protection (ICRP) Committee 2 since 2017.

$\mathrm{He}$ is the principal investigator of the development team of a general-purpose Monte Carlo particle transport simulation code PHITS, which can handle the transport of nearly all particles over wide energy range. Approximately 4,000 researchers and technicians from all over the world have been registered as PHITS users, and use it for various

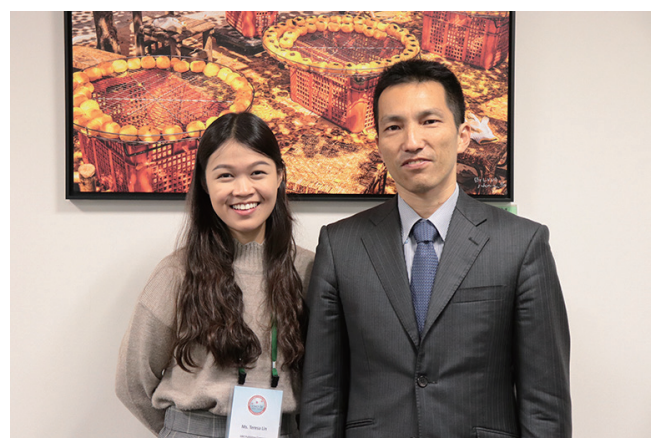

Figure 1 Dr. Tatsuhiko Sato and editor from Therapeutic Radiology and Oncology.

applications such as radiation protection and shielding, medical physics, and cosmic-ray research. His major research themes are radiation biophysics and cosmic-ray dosimetry. He recently published a paper for proposing a new model for estimating the biological effectiveness for BNCT considering intracellular and intercellular heterogeneity in 10B distribution, based on PHITS coupled with the stochastic microdosimetric kinetic model (T. Sato et al., Sci Rep, 2018;8:988).

\section{Interview (Figure 3)}

\section{TRO: Could you briefly introduce yourself to our readers?}

Dr. Sato: I started my research career as a nuclear physicist. I graduated from the department of nuclear engineering, Kyoto University in Japan, and got a researcher position at Japan Atomic Energy Research Institute, which was reorganized to Japan Atomic Energy Agency, JAEA. In JAEA, I started to work on developing Particle and Heavy Ion Transport code System, PHITS. As applications of the PHITS code, I expanded my research area to radiation biology, radiation protection, medical physics, cosmic-ray physics, and space weather physics. 


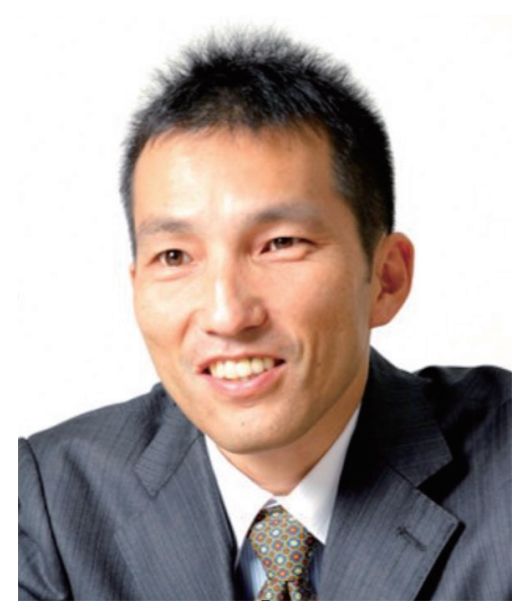

Figure 2 Tatsuhiko Sato, PhD, Researcher, Nuclear Science and Engineering Center, Japan Atomic Energy Agency.

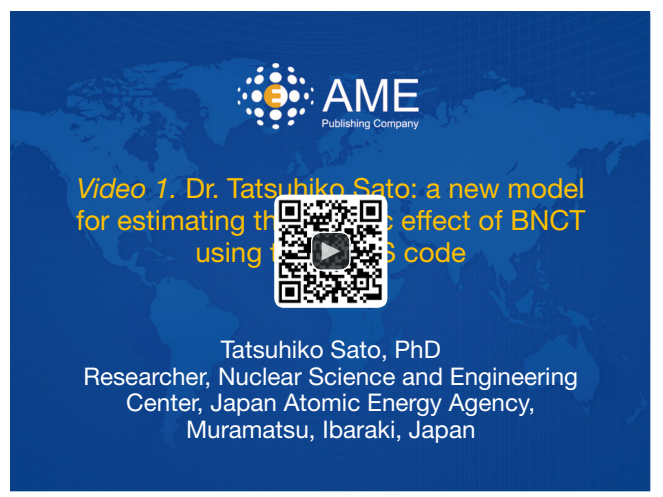

Figure 3 Dr. Tatsuhiko Sato: a new model for estimating therapeutic effect of BNCT using the PHITS code (1). Available online: http://www.asvide.com/article/view/28554

\section{TRO: What are the features of the PHITS code?}

Dr. Sato: PHITS is a Monte Carlo-based particle transport simulation code that can analyze the motion of any radiation in any matter. It is an all-in-one-package type of code, which means all contents of PHITS such as source files and data libraries are fully integrated into one package and then distributed to many countries via OECD/ NEA databank and RSICC. Approximately 4,000 users have been registered and used it for various applications such as accelerator design, medical physics, and space and geosciences. Among them, the application aspect of medical physics is really a growing-up area, such as the development of a treatment planning system based on the PHITS code.
TRO: You recently developed a model for estimating therapeutic effect of boron neutron capture therapy, BNCT, using the PHITS code. Could you briefly explain the model to us?

Dr. Sato: BNCT is known as a cellular-level therapeutic modality. Boron compounds are selectively taken into tumor cells, and when they are irradiated by neutrons, boron would capture a neutron and emit an alpha particle and a Lithium-ion, which stop within the cell or neighboring cell. Therefore, absorbed doses in each tumor cell have large heterogeneity because the boron compounds that are taken into each cell also have large heterogeneity. The most important feature of our model is that it is based on the cellular-scale doses. However, it is nearly impractical to evaluate the doses in each cell in the human body. So, we convert the cellular-scale dose to cell surviving fraction using our original microdosimetry model called SMK and coupled with the PHITS code, and estimate the therapeutic effect of BNCT by calculating the photon dose to give the same surviving fraction, so-called photon isoeffective dose.

\section{TRO: How do you plan to apply your model to BNCT?}

Dr. Sato: Our model is still in the research stage. For example, it is based on cell surviving fraction, but the therapeutic effect is not proportional to the surviving fraction. We need to improve the model to be capable of estimating tumor control probability (TCP), or normal tissue complication probability (NTCP). When we finish the improvement, we would like to implement the model into the treatment planning system of BNCT, based on the PHIPS code, and use it for more precise optimization of its clinical protocol. Aside from that, I think that our model can contribute to drug discovery research. Right now, T/N ratio, the concentration of compounds in tumor and normal cell, is the most important factor to determine whether the compound is suitable for BNCT or not. Also, it is known that intercellular heterogeneity of compound is also a very important factor, and our model can quantitatively estimate the heterogeneous effect.

\section{TRO: You have studies various research fields. Why did you devote yourself to BNCT?}

Dr. Sato: BNCT research is an interdisciplinary field indeed. It consists of radiation physics, biology, chemistry, and oncology. I love to work with researchers from other fields because we can always inspire each other. BNCT 
radiation fields consist of four dose components, boron, hydrogen, nitrogen, and photon doses. These four components are evaluated separately, which means their synergetic effects are not taken into account for the current treatment planning system of BNCT. One important feature of my model is that it can take the synergetic effects between the dose components into consideration. Therefore, I would also like to create synergies between the different research areas of BNCT consortium itself.

\section{Acknowledgments}

Funding: None.

\section{Footnote}

Provenance and Peer Review: This article was commissioned by the editorial office, Therapeutic Radiology and Oncology for the series "Meet the Professor". The article did not undergo external peer review.

Conflicts of Interest: The author has completed the ICMJE uniform disclosure form (available at http://dx.doi. org/10.21037/tro.2018.11.02). The series "Meet the Professor" was commissioned by the editorial office without any funding or sponsorship. Teresa Lin reports that she is a full-time employee of AME publishing company (publisher

doi: $10.21037 /$ tro.2018.11.02

Cite this article as: Lin T. Dr. Tatsuhiko Sato: a new model for estimating therapeutic effect of BNCT using the PHITS code. Ther Radiol Oncol 2018;2:56. of the journal). The author has no other conflicts of interest to declare.

Ethical Statement: The author is accountable for all aspects of the work in ensuring that questions related to the accuracy or integrity of any part of the work are appropriately investigated and resolved.

Open Access Statement: This is an Open Access article distributed in accordance with the Creative Commons Attribution-NonCommercial-NoDerivs 4.0 International License (CC BY-NC-ND 4.0), which permits the noncommercial replication and distribution of the article with the strict proviso that no changes or edits are made and the original work is properly cited (including links to both the formal publication through the relevant DOI and the license). See: https://creativecommons.org/licenses/by-nc-nd/4.0/.

\section{References}

1. Lin T. Dr. Tatsuhiko Sato: a new model for estimating therapeutic effect of BNCT using the PHITS code. Asvide 2018;5:871. Available online: http://www.asvide. com/article/view/28554

(Science Editor: Teresa Lin, TRO, tro@amegroups.com) 